\title{
Vector Analysis and Optimal Control for the Voltage Regulation of a Weak Power System with Wind Energy and Power Electronics
}

\author{
Nick Schinas ${ }^{1}$ \\ ${ }^{1}$ Technological Educational Institute of Western Greece, Patras, Greece \\ Correspondence: Nick Schinas, Technological Educational Institute of Western Greece, Patras, Greece. E-mail: \\ nickschinas@gmail.com,nschinas@teiwest.gr
}

Received: September 14, 2018

Accepted: October 1, 2018

Online Published: November 30, 2018

doi:10.5539/apr.v10n6p1

URL: https://doi.org/10.5539/apr.v10n6p1

\begin{abstract}
This paper deals with the voltage regulation in a weak system which contains large inductive loads and wind turbines using Doubly Fed Induction Generators (FDIGs). The DFIGs demand large amounts of reactive power from the grid and as a result, there is a voltage drop in the system which may be extra deteriorated if large inductive loads and motors are also present in the same line. The problem of the voltage regulation in these cases is treated with the installation of a Static Var Compensator (SVC) besides the capability of the DFIGs to partially regulate the voltage themselves. In this paper, new modeling procedures based on optimal control are developed for the design of the SVC controller and a novel strategy for the grid side converter of the DFIG is presented. The nonlinear system is simulated in the SIMULINK software so that the performance of the new controllers is validated.
\end{abstract}

Keywords: wind turbine, voltage regulation, doubly fed induction generator, optimal control.

\section{Introduction}

The increased need for wind energy development makes the installation of wind turbines in 'weak' ac grids necessary. On the other hand, many voltage instability incidents have taken place around the world the last years (Custem \& Vournas, 1998; Berizzi, 2004). The distributed generation with wind power stations installed in weak distribution systems may enlarge this problem especially when large inductive loads are connected to the same line. So, voltage regulation has become a major research area in the field of power systems (Chondrogiannis, 2007; Ledesma, 2002; Kesraoui, 2016).

This paper deals with the design of the necessary control loops so that good performance of the grid voltage can be attained in a very weak system which contains a wind park (WP) and large inductive loads. The WP consist of wind turbines with Doubly Fed Induction Generators (DFIGs). The DFIGs demand reactive power from the grid. These amounts of reactive power make the grid voltage very sensitive to load variations. The voltage performance can be improved by means of FACTS devices and better voltage controllers inside the DFIG.

The system under study is shown in Figure 1. A medium voltage line is connected to the main grid at bus 1 with short circuit capability of 150 MVA. There is a steam power generation system (SPGS) at bus 2 with rated power of $50 \mathrm{MVA}$ and a wind park at bus 3 connected to this line. This system can be a part of a local grid in an island to which wind parks are to be installed.

The WP includes 11 wind turbines each with rated real power of $1.5 \mathrm{MW}$. At bus 4 there are inductive loads with rated power of 2 MVA and power factor 0.9 lagging. These loads also include three asynchronous motors each rated $300 \mathrm{~kW}$. The nominal line voltage of the system is $25 \mathrm{kV}$. The variation of the reactive power demanded from the WP causes the load voltage at all buses to deviate from the rated values despite the presence of the SPGS in the system. At $\mathrm{t}=50 \mathrm{sec}$ there is an increase in the wind speed from $8 \mathrm{~m} / \mathrm{s}$ to $14 \mathrm{~m} / \mathrm{s}$ and at $\mathrm{t}=75 \mathrm{sec}$ the large induction motors start to operate. Figure 2 shows the rms value of the load voltage at bus 4 . The real power produced from the WP is shown in Figure 3 and the reactive power from the WP is shown in Figure 4. The real power production of the SPGS is kept constant at $15 \mathrm{MW}$. 


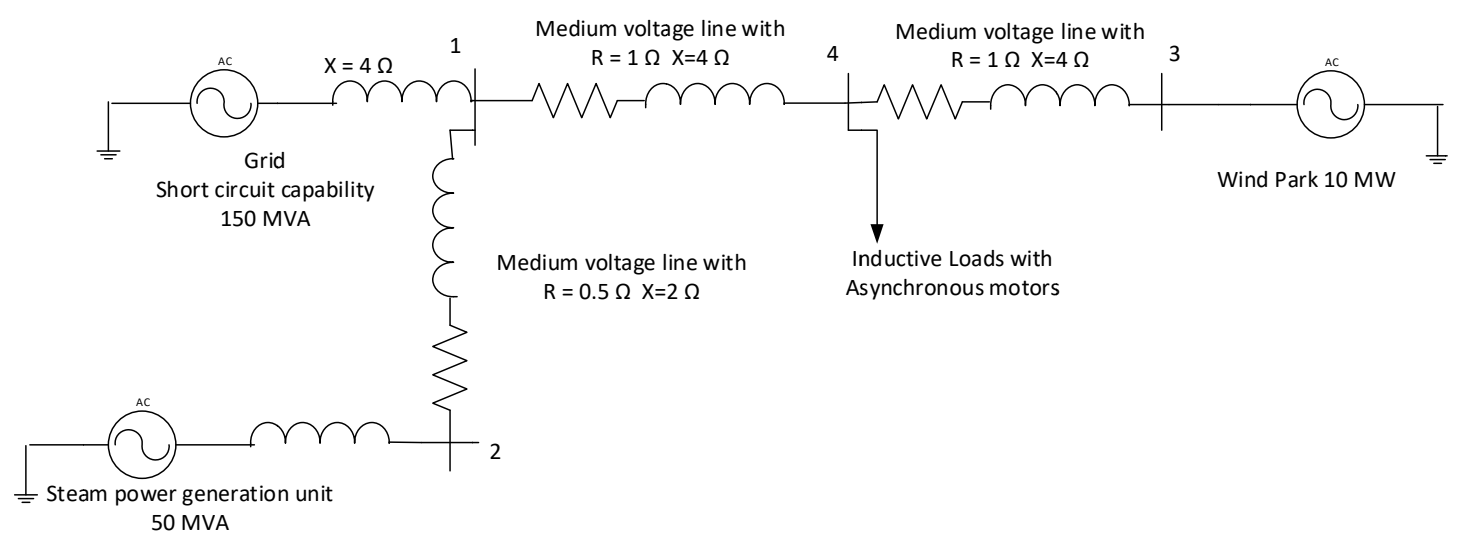

Figure 1. System under study

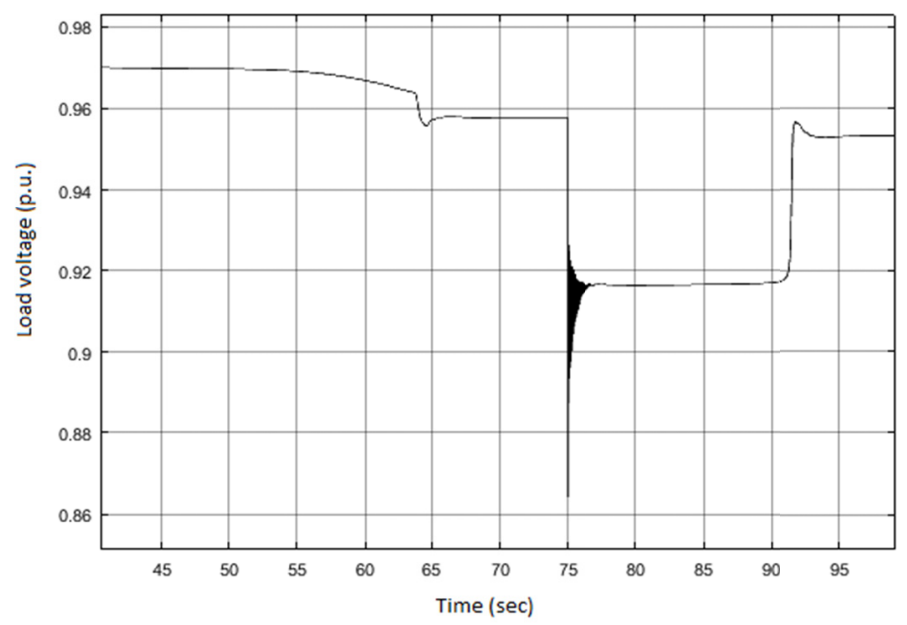

Figure 2. RMS load voltage in p.u.

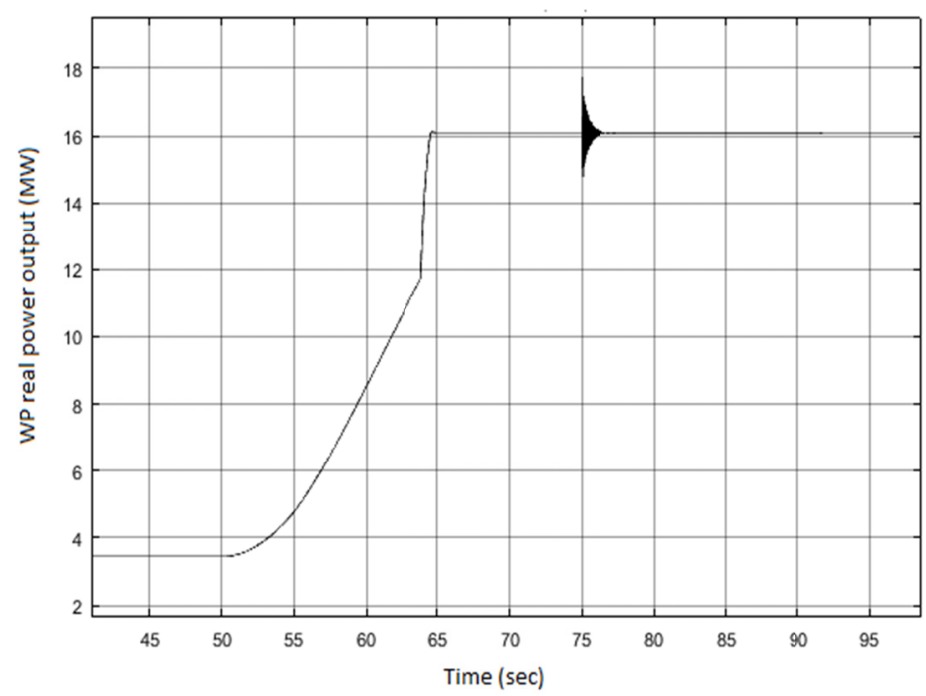

Figure 3. Real power from the WP (MW) 


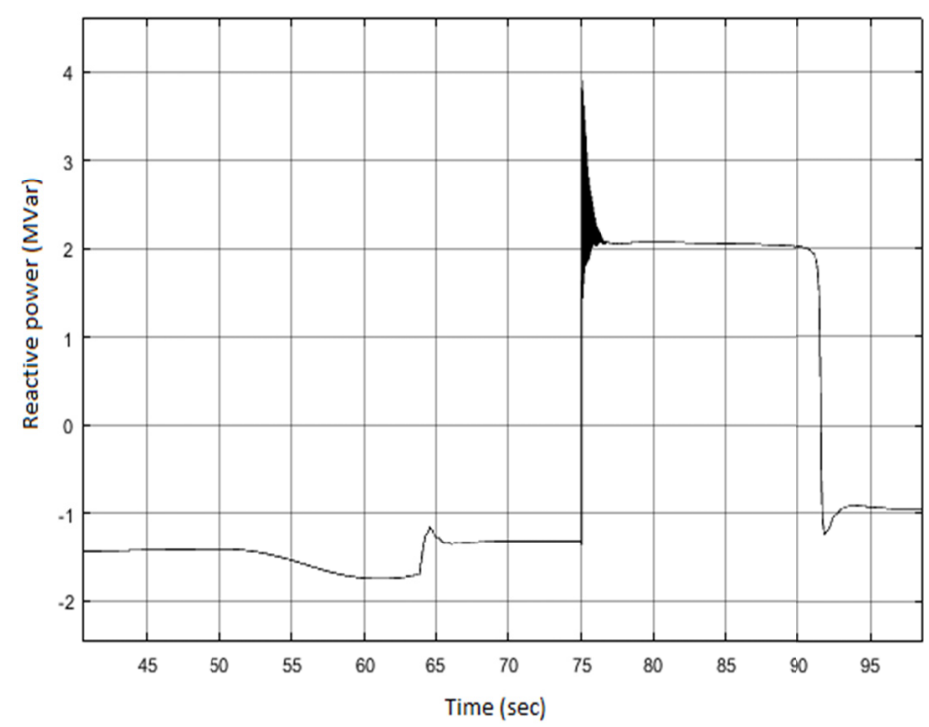

Figure 4. Reactive power from the WP in MVars

As we can see, the grid voltage starts to decrease from the rated value when the wind speed increases due to the fact that the reactive power from the grid towards the WP increases. From $t=50 \mathrm{sec}$ up to $t=70 \mathrm{sec}$ the WP causes a voltage drop of about $2 \%$ to the system. The grid voltage decreases significantly during the start of the asynchronous motors in which the reactive power exchange between the grid and the WP changes direction. This change in the direction of the reactive power stresses the various electronic components of the system especially those of the wind turbines. Finally, the steady state voltage drop to the load bus after the insertion of the motors is about $5 \%$ while without the presence of the WP the steady state voltage drop would be $3 \%$.

What happens if we try to add one more wind turbine into the system? Figure 5 shows the rms load voltage after the insertion of the motors and Figure 6 shows the real power coming from the WP. We can see that the load voltage takes very low values now and there is a serious oscillation after the start of the motors. The real power from the WP also oscillates and does not increase. This actually means that this wind turbine cannot be connected to the line.

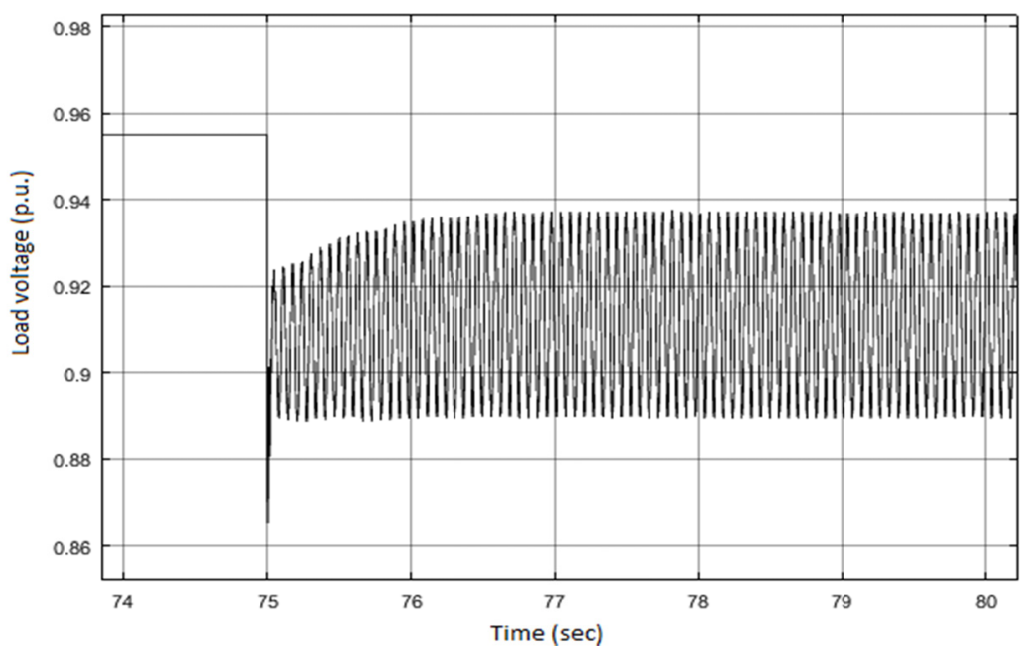

Figure 5. Load voltage with 12 wind turbines 


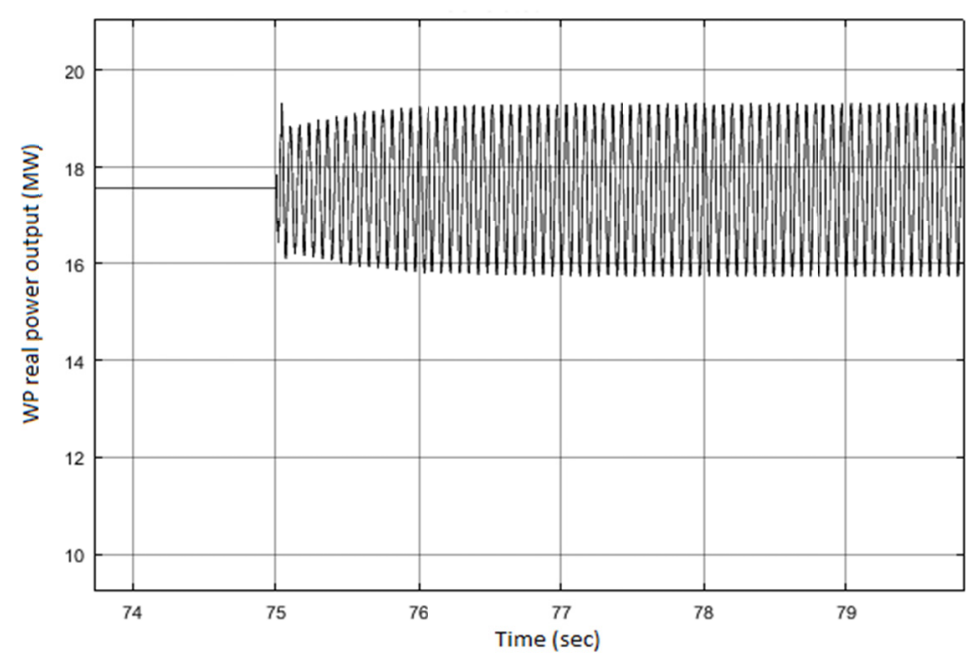

Figure 6. Real power from the WP with 12 wind turbines

The improvement of the grid voltage performance can be achieved by means of the installation of a Static Var Compensator (SVC) at the bus 1 and the proper design of the current regulator of the grid-side controller of the WT. The purpose of this paper is the presentation of new methods based on optimal control theory for the design of the SVC controller and the grid-side controller of the WT so that the right amounts of reactive power are injected into the system to stabilize the voltage. As we shall see, the improved performance of the voltage permits two more wind turbines to be connected to the line which means that higher penetration of wind energy can be accomplished in weak systems if good voltage regulation is achieved.

\section{Description and modeling of the system}

\subsection{Mathematical model of the generator and the power line between the buses 1-2}

The mathematical model in p.u. of the synchronous generator (SG) of the SPGS is (Padiyar, 2014):

$$
\begin{gathered}
\frac{1}{\omega_{s}} \frac{d \psi_{d}}{d t}=R_{s} i_{d}+\frac{\omega}{\omega_{s}} \psi_{q}+v_{d} \\
\frac{1}{\omega_{s}} \frac{d \psi_{q}}{d t}=R_{s} i_{q}-\frac{\omega}{\omega_{s}} \psi_{d}+v_{q} \\
T^{\prime}{ }_{d o} \frac{d E^{\prime} q}{d t}=-E^{\prime}{ }_{q}-\left(X_{d}-X^{\prime}{ }_{d}\right) i_{d}+E_{f d} \\
T^{\prime}{ }_{q o} \frac{d E^{\prime} d}{d t}=-E^{\prime}{ }_{d}+\left(X_{q}-X^{\prime}{ }_{q}\right) i_{q} \\
\frac{d \delta}{d t}=\omega-\omega_{s} \\
\frac{2 H}{\omega_{s}} \frac{d \omega}{d t}=T_{m}-\left(\psi_{d} i_{q}-\psi_{q} i_{d}\right)-T_{D}
\end{gathered}
$$

where:

$\psi_{\mathrm{d}}, \quad \psi_{\mathrm{q}}$ are the d,q components of the stator magnetic flux respectively,

$\mathrm{i}_{\mathrm{d}}, \mathrm{i}_{\mathrm{q}}$ are the $\mathrm{d}, \mathrm{q}$ components of the stator current respectively,

$\mathrm{v}_{\mathrm{d}}, \mathrm{V}_{\mathrm{q}}$ are the $\mathrm{d}, \mathrm{q}$ components of the stator voltage respectively,

$\mathrm{E}_{\mathrm{q}}{ }_{\mathrm{q}}, \mathrm{E}_{\mathrm{d}}{ }_{\mathrm{d}}$ are the $\mathrm{d}, \mathrm{q}$ components of the stator internal transient voltage respectively,

$X_{d}\left(=X_{l s}+X_{m d}\right)$ is the $d$ axis reactance, $X_{q}\left(=X_{l s}+X_{m q}\right)$ is the $q$ axis reactance,

$\mathrm{X}_{\mathrm{d}}{ }_{\mathrm{d}}\left(=\mathrm{X}_{\mathrm{d}}-\mathrm{X}_{\mathrm{md}}^{2} \mathrm{X}_{\mathrm{fd}}\right)$ is the $\mathrm{d}$ axis transient reactance, 
$\mathrm{X}_{\mathrm{q}}^{\prime}\left(=\mathrm{X}_{\mathrm{q}}-\mathrm{X}_{\mathrm{mq}}^{2} / \mathrm{X}_{1 \mathrm{q}}\right)$ is the $\mathrm{q}$ axis transient reactance,

$\omega$ is the rotor electrical angular speed, $\omega_{S}$ is the electrical speed of the magnetic flux,

$\delta$ is the power angle, $H$ is the inertia constant,

$T_{m}$ is the mechanical torque, $T_{D}$ is the damping torque (being neglected from now on).

Finally, $\mathrm{T}_{\mathrm{do}}, \mathrm{T}_{\mathrm{qo}}$ are time constants on field and damper winding respectively (we consider the machine to have one damping winding on $\mathrm{q}$ axis) and $\mathrm{R}_{\mathrm{s}}$ is the stator resistance.

By neglecting the equations regarding the stator magnetic fluxes (equations (a) and (b) above) and replacing the relevant values from the Appendix we have:

$$
\begin{gathered}
\frac{d E^{\prime} q}{d t}=-0.22 E_{q}^{\prime}-0.31 i_{d}+0.22 E_{f d} \\
\frac{d E^{\prime} d}{d t}=-1.5 E_{d}^{\prime}+1.7 i_{q} \\
\frac{d \delta}{d t}=\omega-314
\end{gathered}
$$

It also is:

$$
\psi_{d}=-x_{d}^{\prime} i_{d}+E^{\prime}{ }_{q}, \quad \psi_{q}=-x^{\prime}{ }_{q} i_{q}-E^{\prime}{ }_{d}
$$

By replacing to (4a) we finally reach in:

$$
\frac{d \omega}{d t}=180.46 T_{m}-180.46 E^{\prime}{ }_{q} i_{q}-180.46 E^{\prime}{ }_{d} i_{d}+37.89 i_{d} i_{q}
$$

As we have already seen, the SPGS is connected to the bus 2 and there is a small line up to the main bus 1 . The Figure 7 depicts the vectors of the voltages at the buses. The voltage $v_{2}$ at the bus 2 will be a little ahead of the voltage $\mathrm{v}_{1}$ at the bus 1 (approximately 3 degrees). We consider the main axes $\mathrm{D}, \mathrm{Q}$ and the axes $\mathrm{d}$, $\mathrm{q}$ internally in the synchronous generator to which the various quantities of the SG have been analyzed in the equations (1b)-(4b). We arbitrarily consider that the voltage $\mathrm{v}_{2}$ is lying on the $\mathrm{D}$ axis.

The stator current $i$ of the $S G$ with its components $i_{d}, i_{q}$ onto the axes $d$, $q$ is also the current $I$ of the line between the buses 2 and 1 with the components $\mathrm{I}_{\mathrm{D}}, \mathrm{I}_{\mathrm{Q}}$ onto the axes $\mathrm{D}, \mathrm{Q}$ respectively. It is (Pai et al., 2014):

$$
i_{d}=I_{D} \sin \delta-I_{Q} \cos \delta, i_{q}=I_{D} \cos \delta+I_{Q} \sin \delta
$$

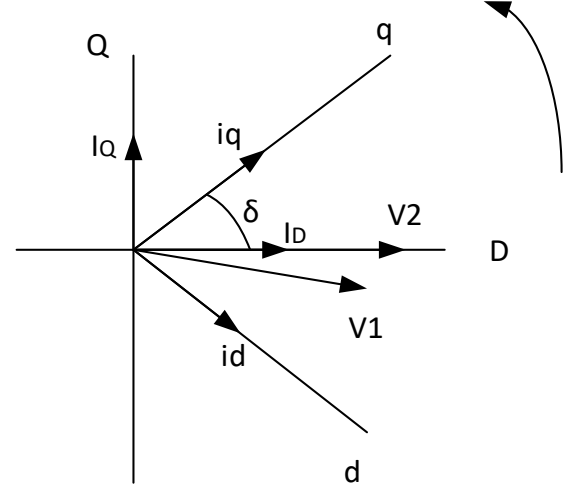

Figure 7. Vector analysis of the system

Applying the D-Q analysis on the line between the buses 2 and 1 we have firstly on the D axis:

$$
V_{2 D}=V_{1 D}+R_{2-1} I_{D}+L_{2-1} \frac{d I_{D}}{d t}+X_{2-1} I_{Q} \Rightarrow V_{2 D}-V_{1 D}=R_{2-1} I_{D}+L_{2-1} \frac{d I_{D}}{d t}+X_{2-1} I_{Q}
$$

Due to the small value of the angle between $\mathrm{v}_{1}$ and $\mathrm{v}_{2}$ it is approximately: $V_{2 D}-V_{1 D} \approx 0$. So from the previous equation we conclude to: 


$$
L_{2-1} \frac{d I_{D}}{d t}=-R_{2-1} I_{D}-X_{2-1} I_{Q}
$$

and by replacing the values from the Appendix we have:

$$
\frac{d I_{D}}{d t}=-0.35 I_{D}-I_{Q}
$$

From the line analysis on the axis Q we have:

$$
V_{2 Q}=V_{1 Q}+R_{2-1} I_{Q}+L_{2-1} \frac{d I_{Q}}{d t}-X_{2-1} I_{D} \Rightarrow V_{2 Q}-V_{1 Q}=R_{2-1} I_{Q}+L_{2-1} \frac{d I_{Q}}{d t}-X_{2-1} I_{D}
$$

By taking into account that $\mathrm{v}_{2 \mathrm{Q}}=0$ and by replacing the values we have:

$$
\frac{d I_{Q}}{d t}=-0.35 I_{Q}+I_{D}-3.8 V_{1 Q}
$$

The equations (1b)-(4b) can be rewritten if we replace the quantities $i_{d}$, $i_{q}$ by $I_{D}, I_{Q}$ using the equation ( $5 a$ ). Then we can reach in:

$$
\begin{gathered}
\frac{d E^{\prime} q}{d t}=-0.22 E^{\prime}{ }_{q}-0.31 I_{D} \sin \delta+0.31 I_{Q} \cos \delta+0.22 E_{f d} \\
\frac{d E^{\prime} d}{d t}=-1.5 E^{\prime}{ }_{d}+1.7 I_{D} \cos \delta+1.7 I_{Q} \sin \delta \\
\frac{d \delta}{d t}=\omega-314 \\
\frac{d \omega}{d t}=180.46 T_{m}-180.46 E^{\prime}{ }_{q} I_{D} \cos \delta-180.46 E^{\prime}{ }_{q} I_{Q} \sin \delta-180.46 E^{\prime}{ }_{d} I_{D} \sin \delta+180.46 E^{\prime}{ }_{d} I_{Q} \cos \delta- \\
-18.95 I_{D}^{2} \sin 2 \delta+18.95 I_{Q}^{2} \sin 2 \delta-37.89 I_{D} I_{Q} \sin ^{2} \delta+37.89 I_{D} I_{Q} \cos ^{2} \delta
\end{gathered}
$$

The nonlinear system that consists of the voltage $\mathrm{v}_{1}$ at the bus 1 and the internal quantities of the SG is actually described by the equations (1)-(6). By linearizing the above equations around the operating point given at the Appendix we finally conclude to the linear system given by the following equations:

$$
\begin{gathered}
\frac{d \Delta E^{\prime} q}{d t}=-0.22 \Delta E_{q}^{\prime}-0.06 \Delta \delta-0.155 \Delta I_{D}+0.27 \Delta I_{Q}+0.22 \Delta E_{f d} \\
\frac{d \Delta E^{\prime} d}{d t}=-1.5 \Delta E^{\prime}{ }_{d}-0.385 \Delta \delta+1.47 \Delta I_{D}+0.85 \Delta I_{Q} \\
\frac{d \Delta \delta}{d t}=\Delta \omega-314 \\
\frac{d \Delta \omega}{d t}=-37.45 \Delta{E^{\prime}}_{q}-40.89 \Delta E^{\prime}{ }_{d}+20.7 \Delta \delta+137.2 \Delta I_{D}-25 \Delta I_{Q}+180.46 \Delta T_{m} \\
\frac{d \Delta I_{D}}{d t}=-0.35 \Delta I_{D}-\Delta I_{Q} \\
\frac{d \Delta I_{Q}}{d t}=-0.35 \Delta I_{Q}+\Delta I_{D}-3.8 \Delta V_{1 Q}
\end{gathered}
$$

The equations (7)-(12) form the linearized model of the SG and the line between the buses 1 and 2.

\subsection{Model of the grid-side converter of the WT}

A schematic configuration of the grid side converter, is shown in Figure 8 in which the grid phase voltages are denoted as $\mathrm{e}_{\mathrm{a}}, \mathrm{e}_{\mathrm{b}}, \mathrm{e}_{\mathrm{c}}$ and the converter phase voltages as $\mathrm{v}_{\mathrm{a}}, \mathrm{v}_{\mathrm{b}}, \mathrm{v}_{\mathrm{c}}$ are respectively. The $\mathrm{d}, \mathrm{q}$ components $\left(\mathrm{i}_{\mathrm{d}}, \mathrm{i}_{\mathrm{q}}\right)$ of the line currents $\mathrm{i}_{\mathrm{a}}, \mathrm{i}_{\mathrm{b}}, \mathrm{i}_{\mathrm{c}}$ concerning the $\mathrm{d}, \mathrm{q}$ components $\left(\mathrm{v}_{\mathrm{d}}, \mathrm{v}_{\mathrm{q}}\right)$ of the converter voltages $\mathrm{v}_{\mathrm{a}}, \mathrm{v}_{\mathrm{b}}, \mathrm{v}_{\mathrm{c}}$ can be given by the following equations (Vittal \& Ayyanar, 2013): 


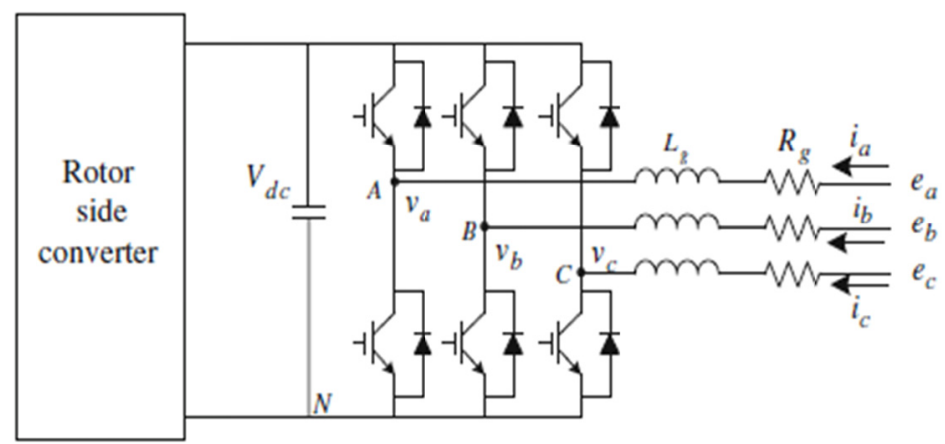

Figure 8. Grid side converter configuration (Vittal \& Ayyanar, 2013)

$$
L_{g} \frac{d i_{d}}{d t}=-R_{g} i_{d}+\omega_{s} L_{g} i_{q}+e_{d}-v_{d}, \quad L_{g} \frac{d i_{q}}{d t}=-R_{g} i_{q}-\omega_{s} L_{g} i_{d}-v_{q}
$$

The modeling of the converter of the WT and its control design has nothing to do with the rest of the system, so the choice of the WT d,q, axes is arbitrary. The grid voltage e has been chosen to lie on the $\mathrm{d}$ axis and so $\mathrm{e}_{\mathrm{q}}=0$. By replacing the p.u. values from the Appendix we reach in the following equations:

$$
\frac{d i_{d}}{d t}=-0.01 i_{d}+i_{q}+6.67 e_{d}-6.67 v_{d}, \quad \frac{d i_{q}}{d t}=-0.01 i_{q}-i_{d}-6.67 v_{q}
$$

As there is the SPGS in our system with installed capacity much larger that the rated output of the WP, the frequency is assumed to be constant and that it does not depend on the real power coming from the WP. As a result, the parameter $\omega_{s}$ has been set equal to 1 . Besides, the parameter $e_{d}$ is considered to be a disturbance for the control system and not an input and so the linearized model for the control design of the grid side converter is given by:

$$
\frac{d \Delta i_{d}}{d t}=-0.01 \Delta i_{d}+\Delta i_{q}-6.67 \Delta v_{d}, \quad \frac{d \Delta i_{q}}{d t}=-0.01 \Delta i_{q}-\Delta i_{d}-6.67 \Delta v_{q}
$$

\section{Control SYSTEM DESIGN}

\subsection{SVC Controller Design}

In order for the load voltage to be kept constant under reactive power from the WP and the load variations, an SVC installation is proposed at the bus 1 of the system. The SVC is actually a device with variable susceptance through which fast power factor improvement can be achieved. Figure 9 shows a typical SVC (TSC-TCR) configuration. There is a main voltage controller which according to the deviation of the bus voltage from the rated value regulates the right susceptance being connected to the bus and so the right amount of reactive power being inserted into the system. A block diagram of SVC voltage control is depicted in Figure 10. There can be more auxiliary signals in the decision of the right susceptance (B) of the SVC control, like the signals $\mathrm{V}_{\mathrm{s}}$ shown in Figure 10. There are no such signals in our study. The connected susceptance at the bus 1 will force the magnitude of the voltage at the bus 1 to change. If only the fundamental component of Vsvc is considered, we can assume that:

$$
\Delta V_{s v c} \cong X \Delta B_{s v c}
$$

that is, the variation of the magnitude of the voltage at the bus where the SVC is installed (i.e. bus 1) depends on the variation of the susceptance of the $\mathrm{SVC}(\triangle \mathrm{Bsvc})$. $\mathrm{X}$ is the equivalent Thevenin resistance of the grid as seen from the bus 1 . 


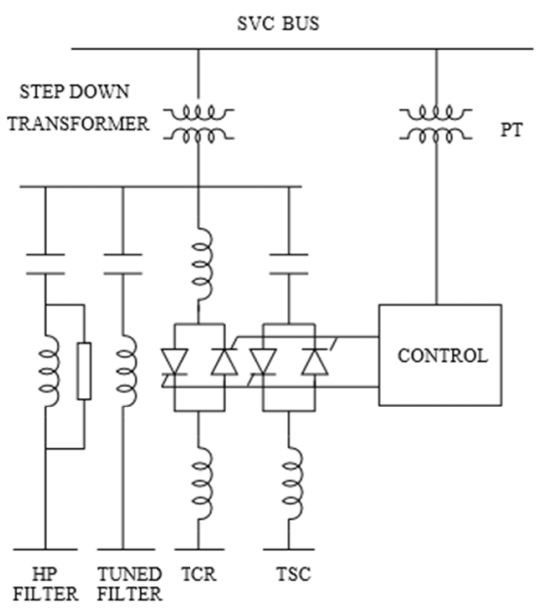

Figure 9. Typical configuration of SVC (TSC-TCR) configuration (Padiyar, 2014)

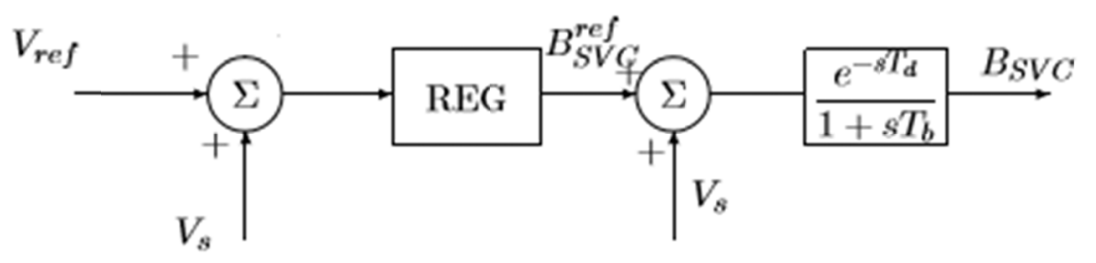

Figure 10. SVC voltage control with series regulator (Padiyar, 2014)

The equations (7)-(12) form the linearized model concerning the SPGS and the line between the buses 1 and 2 . The SPGS is considered to produce steady real power into the system and so the angle $\delta_{1}$ is almost constant, that is:

$$
V_{1 Q}=\left|V_{1}\right| \sin \delta_{1} \Rightarrow \Delta V_{1 Q}=\sin \delta_{1 o}\left|\Delta V_{1}\right| \Rightarrow \Delta V_{1 Q}=\sin \delta_{1 o} V_{1 o} X \Delta B_{s v c} \Rightarrow \Delta V_{1 Q}=0.035 \Delta B_{s v c} p . u \text {. }
$$

In the model given by (7)-(12) the input to the system will actually be the change in the susceptance $\Delta B_{s v c}$ but we set for now as input the variation of the voltage $\Delta \mathrm{V}_{1 \mathrm{Q}}$ and the calculated input will be transformed into the equivalent susceptance value in the end.

For the output to be selected, we need a signal that will follow the voltage variation. As we can see from Figure 11, the q-axis component of the stator current $i_{q}$ of the synchronous generator has the same performance as the load voltage. From the equation (5a) it is:

By linearizing we get:

$$
i_{q}=I_{D} \cos \delta+I_{Q} \sin \delta
$$

$$
\Delta i_{q}=0.866 \Delta I_{D}+0.5 \Delta I_{Q}-0.21 \Delta \delta
$$

So, in the linearized model of the equations (7)-(12) the equation (14) regarding the output of the system must be added. The equations (7)-(12) and the equation (14) form a system of $6^{\text {th }}$ order. By means of MATLAB software, we can reach in a new $2^{\text {nd }}$ order system which is equivalent to the previous one. The new system is given in state space form $\dot{x}=A x+B u, y=C x+D u$ :

$$
A=\left[\begin{array}{cc}
-0.5246 & 0 \\
0 & 4.857
\end{array}\right], B=\left[\begin{array}{c}
1.219 \\
-0.0225
\end{array}\right], C=[-1.2193 .025], D=0, x=\left[\begin{array}{l}
x_{1} \\
x_{2}
\end{array}\right]
$$

The design of the SVC controller is based on the optimal control theory. We want the variations of the state variables and the output to be minimized within a specific smalltime period $\left(\mathrm{t}_{\mathrm{f}}\right)$. So, the following performance index has been set: 


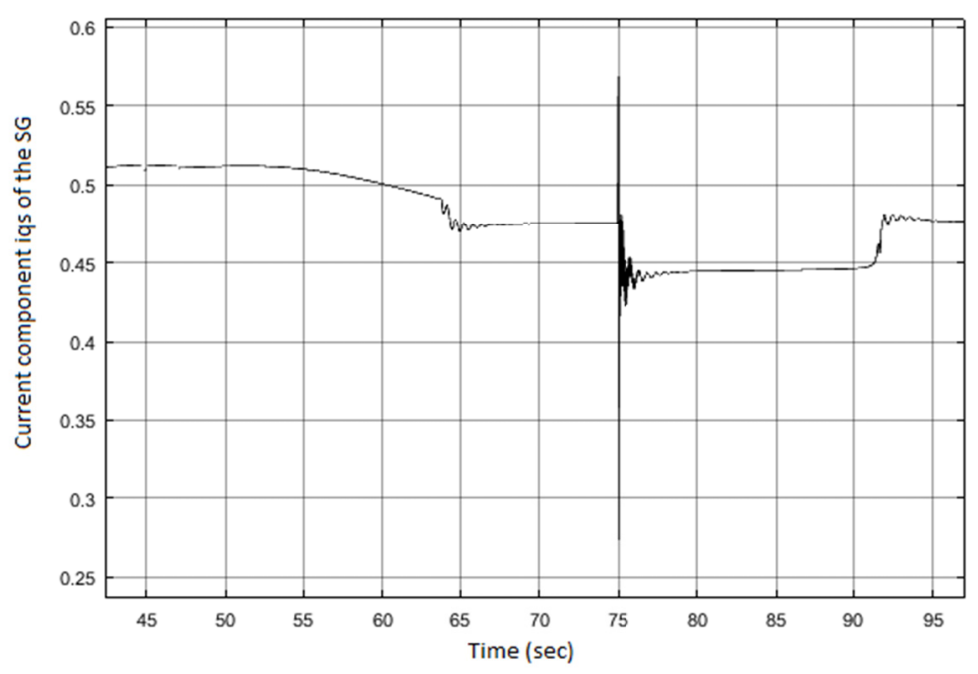

Figure 11. Q-axis component of the current from the SG (p.u.)

which is of the form:

$$
J=\frac{1}{2} \int_{0}^{t_{f}}\left(x_{1}^{2}(t)+x_{2}^{2}(t)+u^{2}(t)\right) d t
$$

$$
J=\frac{1}{2} x^{T}\left(t_{f}\right) F\left(t_{f}\right) x\left(t_{f}\right)+\frac{1}{2} \int_{0}^{t_{f}}\left[x^{T}(t) Q(t) x(t)+u^{T}(t) R(t) u(t)\right] d t
$$

with $\mathrm{F}=0, \mathrm{R}=1$ and $Q=\left[\begin{array}{ll}1 & 0 \\ 0 & 1\end{array}\right]$. According to the optimal control theory, the following matrix differential Riccati equation needs to be solved:

$$
\dot{P}=-P(t) A(t)-A(t)^{T} P(t)+P(t) B(t) R^{-1} B(t)^{T} P(t)-Q(t)
$$

where:

$$
P=\left[\begin{array}{ll}
p_{11} & p_{12} \\
p_{12} & p_{22}
\end{array}\right], \text { with final condition } \mathrm{P}\left(\mathrm{t}=\mathrm{t}_{\mathrm{f}}\right)=\mathrm{F}=0
$$

The optimal input $\mathrm{u}$ is then:

$$
u(t)=-K x(t), \text { with } K=R^{-1} B(t)^{T} P(t) .
$$

From the previous definitions and the matrices A, B, C, D given in equation (15), we finally have the following differential equations for the various elements of the matrix $P$ :

$$
\begin{gathered}
p_{11}^{\cdot}=1.049 p_{11}+1.486 p_{11}^{2}-0.0548 p_{11} p_{12}+0.0005 p_{12}^{2}-1 \\
p_{12}^{\cdot}=-4.3324 p_{12}+1.4586 p_{11} p_{12}-0.0274 p_{12}^{2}+0.0005 p_{12} p_{22} \\
p_{22}=-9.714 p_{22}+1.486 p_{12}^{2}-0.0548 p_{12} p_{22}+0.0005 p_{22}^{2}-1
\end{gathered}
$$

We set the time interval $t_{\mathrm{f}}$ equal to $1 \mathrm{sec}$. Solving the previous set of equations for time interval longer than $1 \mathrm{sec}$ (such as $4 \mathrm{sec}$ ) we can see that the parameters $\mathrm{p}_{11}, \mathrm{p}_{12}, \mathrm{p}_{13}$ are: $\mathrm{p}_{11}=0.55, \mathrm{p}_{12}=0, \mathrm{p}_{22}=190000$. So, the state feedback array $\mathrm{K}$ is equal to: $\mathrm{K}=[0.67-4275]$. According to the equation (16) the optimal control input for the SVC controller should be:

$$
u=-0.67 x_{1}+42752 x_{2}
$$

By transforming this input to the real input $\Delta \mathrm{B}_{\mathrm{SVC}}$ and by means of MATLAB software, the equivalent series controller (as it is shown in Figure 10) is:

$$
G_{c}(s)=\frac{-62.52 s^{2}+273.8 s+145.2}{s^{2}-9.478 s+22.44}
$$

We can see the step response of the linearized model with the optimal control input given by the equation (17) in Figure 12. 


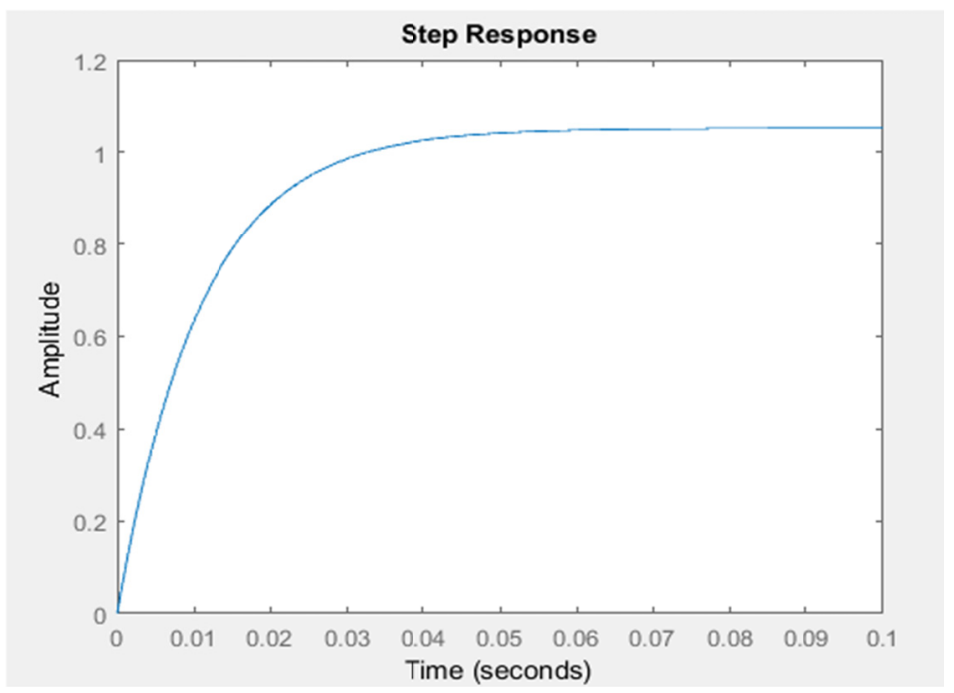

Figure 12. Step response of the linearized model under optimal control.

We can see that the system output gets the desired value in $0.1 \mathrm{sec}$.

\subsection{Grid side converter control design}

The linearized model is given by the equations (13). In state space form if we set

$$
\begin{gathered}
x=\left[\begin{array}{l}
x_{1} \\
x_{2}
\end{array}\right]=\left[\begin{array}{l}
\Delta i_{d} \\
\Delta_{i_{q}}
\end{array}\right], u=\left[\begin{array}{l}
u_{1} \\
u_{2}
\end{array}\right]=\left[\begin{array}{l}
\Delta v_{d} \\
\Delta v_{q}
\end{array}\right], \text { then we can write: } \\
\dot{x_{1}}=-0.01 x_{1}+x_{2}-6.67 u_{1}=f_{1}, \quad \dot{x_{2}}=-0.01 x_{2}-x_{1}-6.67 u_{2}=f_{2}
\end{gathered}
$$

Due to the nature of the above equations we can work with the Hamilton - Jacobi - Bellman (HJB) equation and conclude to a controller very easily. We set the performance index as:

$$
J=\int V(x(t), u(t)) d t=\int\left(x_{1}^{2}+x_{2}^{2}+u_{1}^{2}+u_{2}^{2}\right) d t
$$

and we consider the optimal performance index to

be equal to: $J^{*}=\frac{1}{2} k x_{1}^{2}+\frac{1}{2} k x_{2}^{2}$, then it is: $J_{x}^{*}=\left[\begin{array}{l}\frac{\partial J^{*}}{x_{1}} \\ \frac{\partial J^{*}}{x_{2}}\end{array}\right]=\left[\begin{array}{l}k x_{1} \\ k x_{2}\end{array}\right], J_{t}^{*}=\frac{\partial J^{*}}{\partial t}=0$.

We set the Hamiltonian equation as:

$$
\begin{gathered}
H\left(x(t), u(t), J_{x}^{*}\right)=V(x(t), u(t))+J_{x}^{* T}\left[\begin{array}{l}
f_{1} \\
f_{2}
\end{array}\right]=x_{1}^{2}+x_{2}^{2}+u_{1}^{2}+u_{2}^{2}+\left[k x_{1} k x_{2}\right]\left[\begin{array}{l}
-0.01 x_{1}+x_{2}-6.67 u_{1} \\
-x_{1}-0.01 x_{2}-6.67 u_{2}
\end{array}\right] \\
H\left(x(t), u(t), J_{x}^{*}\right)=x_{1}^{2}+x_{2}^{2}+u_{1}^{2}+u_{2}^{2}-0.01 k x_{1}^{2}-6.67 k x_{1} u_{1}-0.001 k x_{2}^{2}-6.67 k x_{2} u_{2}
\end{gathered}
$$

In order to have optimization there must be:

$$
\frac{\partial H}{\partial u_{1}}=0 \Rightarrow u_{1}^{*}=3.335 k x_{1}, \frac{\partial H}{\partial u_{2}}=0 \Rightarrow u_{2}^{*}=3.335 k x_{2} .
$$

By substitution to the previous we have:

$$
\begin{gathered}
H\left(x(t), u(t), J_{x}^{*}\right)=x_{1}^{2}+x_{2}^{2}+11.12 k^{2} x_{1}^{2}+11.12 k^{2} x_{2}^{2}-0.01 k x_{1}^{2}-0.01 k x_{2}^{2}-22.24 k^{2} x_{1}^{2}-22.24 k^{2} x_{2}^{2} \Rightarrow \\
H\left(x(t), u(t), J_{x}^{*}\right)=\left(1-11.12 k^{2}-0.01 k\right) x_{1}^{2}+\left(1-11.12 k^{2}-0.01 k\right) x_{2}^{2}
\end{gathered}
$$

We solve the HJB equation:

$$
H\left(x(t), u(t), J_{x}^{*}\right)+J_{t}^{*}=0 \Rightarrow\left(1-11.12 k^{2}-0.01 k\right) x_{1}^{2}+\left(1-11.12 k^{2}-0.01 k\right) x_{2}^{2}=0
$$

Now let's recall that $\mathrm{x}_{1}=\Delta \mathrm{i}_{\mathrm{d}}, \mathrm{x}_{2}=\Delta \mathrm{i}_{\mathrm{q}}$. We want the changes in the $\mathrm{d}$ axis (which is responsible for the real power) to be independent on the changes in the q axis (which is responsible for the reactive power). In other words, the 
input $\mathrm{u}$ must make two independent state variables $\mathrm{x}_{1}$ and $\mathrm{x}_{2}$. Having taken this in mind and in order the equation (18) to be true for every $t$, then the optimal solution should be as:

$$
1-11.12 k^{2}-0.01 k=0 \Rightarrow k \approx \pm 0.3 .
$$

We keep the negative sign and hence the control law is:

$$
u_{1}=-x_{1}, u_{2}=-x_{2} .
$$

A very simple equivalent series controller for $\mathrm{i}_{\mathrm{q}}$ is:

$$
G c(s)=-\frac{0.15}{s}
$$

\section{Nonlinear System Simulation Results}

The system as shown in Figure 1 has been simulated now with the addition of an SVC placed at the bus 1 . The SVC voltage controller is given by the equation (17) and the $\mathrm{i}_{\mathrm{q}}$ controller the grid side converter in each WT of the WP is given by the equation (19). As previously, there is a step increase in the wind speed from $8 \mathrm{~m} / \mathrm{sec}$ to $14 \mathrm{~m} / \mathrm{sec}$ at $\mathrm{t}=50 \mathrm{sec}$ and at $\mathrm{t}=75 \mathrm{sec}$ the large induction load with the asynchronous motors is activated. Figure $13 \mathrm{shows}$ the rms value of the load voltage at bus 4 . The real power produced from the WP is the same as in Figure 3 . The reactive power from the WP is shown in Figure 14.

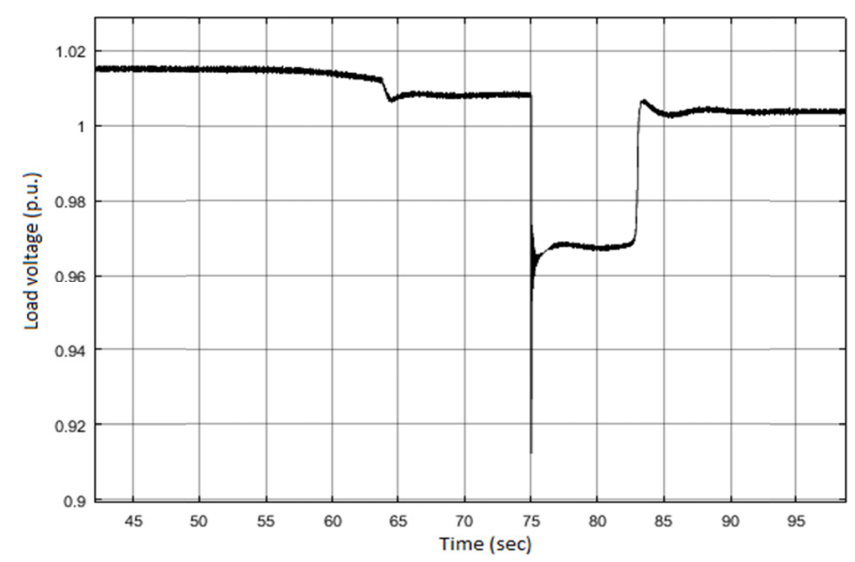

Figure 13. Load voltage with the proposed controllers

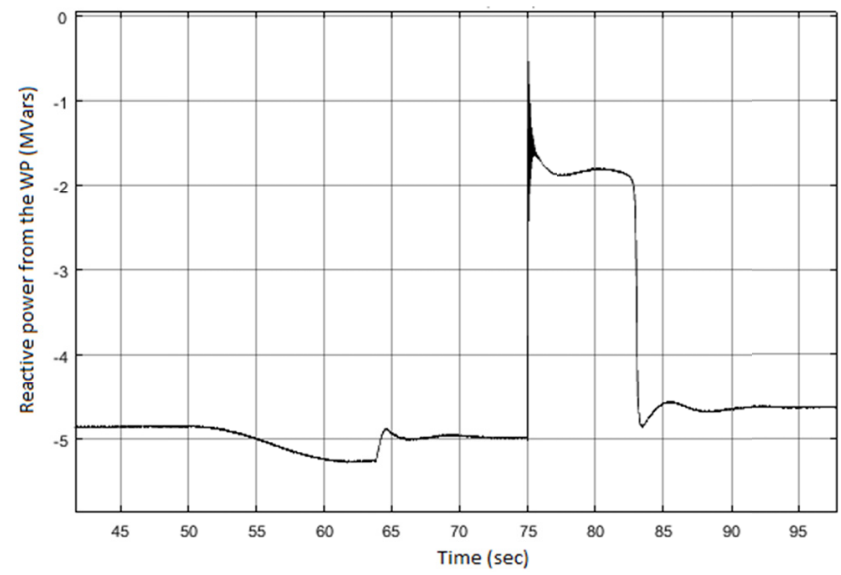

Figure 14. Reactive power towards the WP with the proposed controllers

There is an important improvement in the load voltage. The reactive power demanded by the WP causes now only almost $1 \%$ voltage drop in the system and the reactive power towards the WP does not change direction under the start of the large motors. The voltage drop is about $4 \%$ under the demands for reactive power both from the WP 
and the inductive load during the transient period and almost zero in steady state. Besides, the time duration of the voltage drop for the starting of the motors has been decreased from 15 seconds to less than 10 seconds.

The $d$ component of the grid-side converter current $i_{d}$ is shown in Figure 15 and the q component of the grid-side converter current $i_{q}$ is shown in Figure 16. We can actually see that the two components are independent one from the other and the $i_{d}$ is mostly responsible for the real power output while the $i_{q}$ for the reactive power of the machine.

The proposed control strategy permits the addition of two more machines to be added to the WP which now has rated power as 19.5 MW. The real power coming out from the WP in this case is shown in Figure 17 and the load voltage in Figure 18.

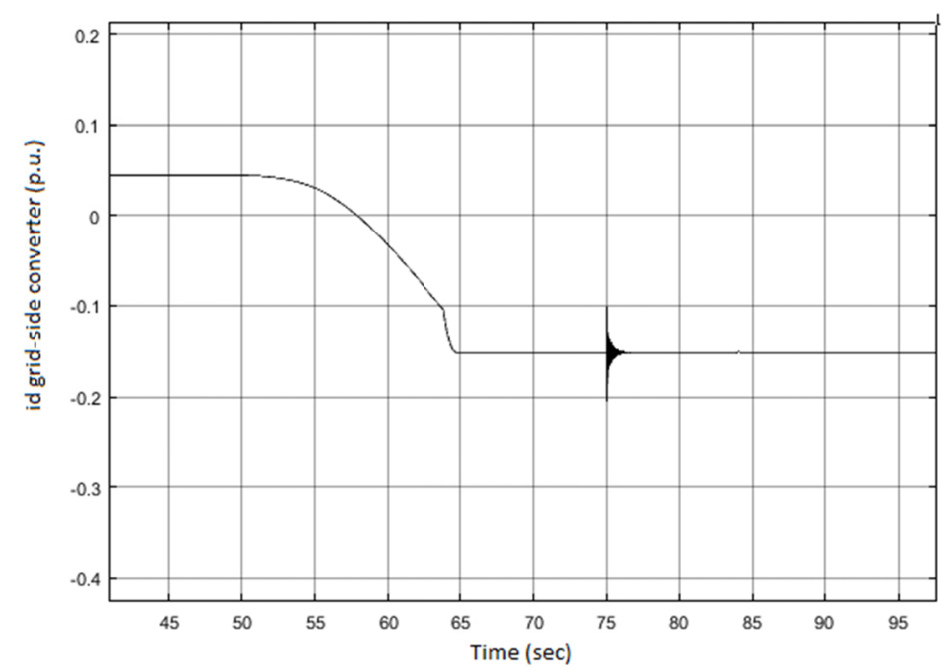

Figure 15. D component of the grid-side converter current

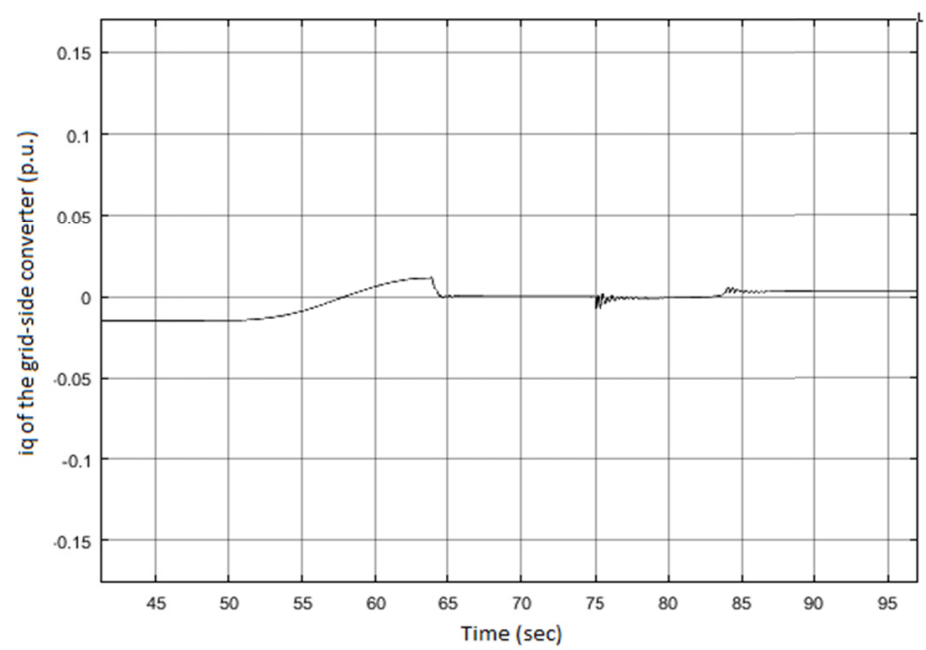

Figure 16. Q component of the grid-side converter current 


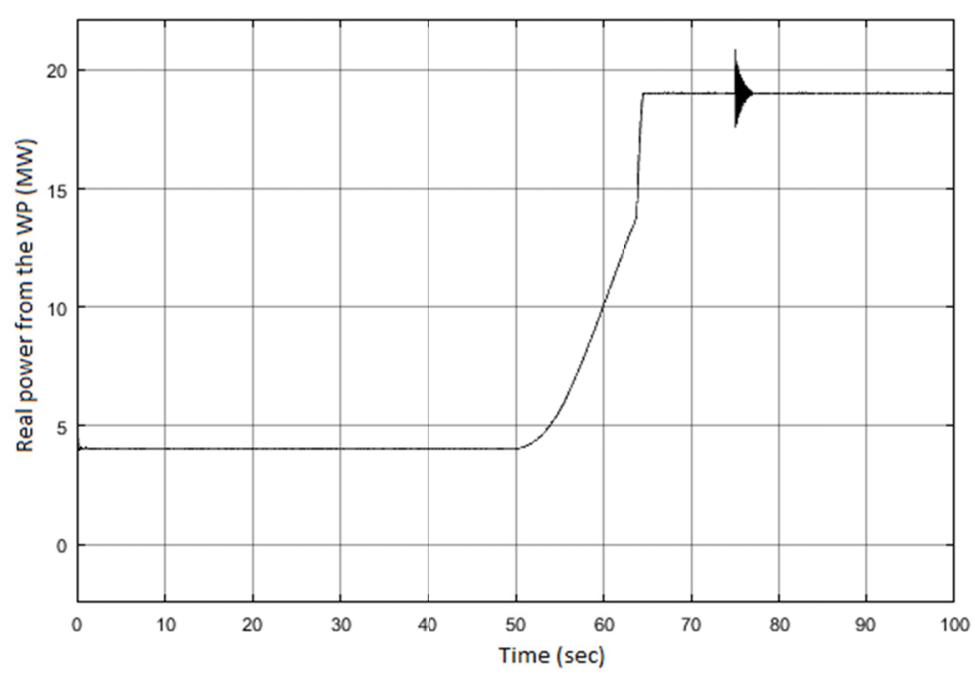

Figure 17. Real power from the WP with 13 wind turbines

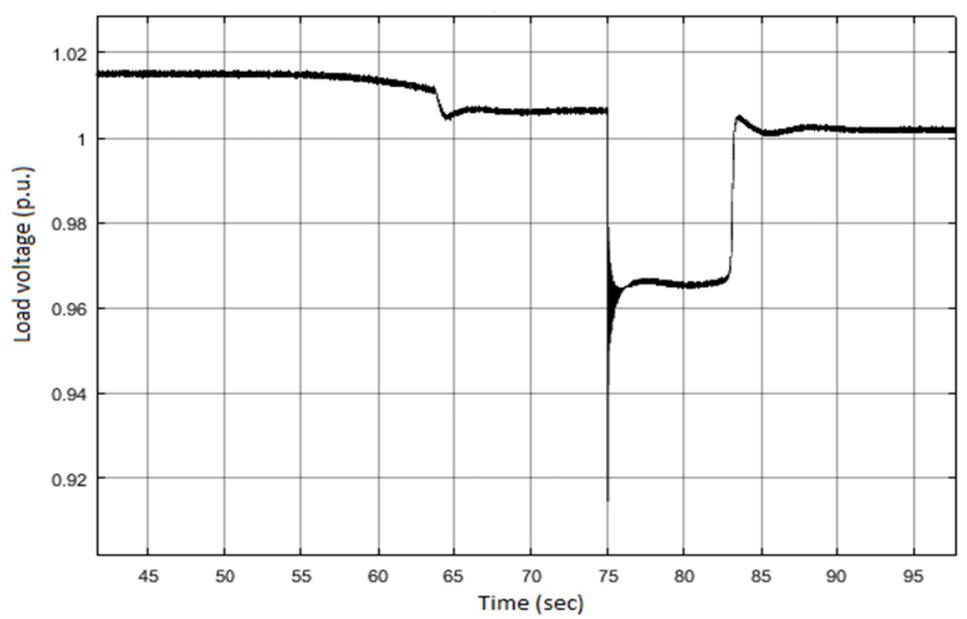

Figure 18. Load voltage with 13 wind turbines

\section{Conclusions}

The insertion of wind turbines with induction generators into weak systems causes extra voltage drops due to the absorbed reactive power from the generators. The low voltage may make the start of large induction motors difficult. The installation of SVC devices along with proper controllers inside the WT can improve the voltage performance in these cases. The proposed methodologies make the design of the necessary controllers easy and can be applied in any weak or local grid. The load voltage was improved significantly after the insertion of the proposed controllers into the system and the penetration of the rated real power from the wind energy was increased.

\section{References}

Custem, T. V., \& Vournas, C. D. (1998). Voltage Stability of the Electric Power System. K. Academic.

Desineni, N. (2003). Optimal Control Systems. CRC Press.

Pai, M. A., \& Gupta, D. P. (2016). Small Signal Analysis of Integrated Power Systems. Alpha Science.

Krause, P. (2010). Analysis of Electrical Machinery. IEEE Press.

Jahangir, H., \& Hemanshu, R. P. (2014). Robust Control for Grid Voltage Stability: High Penetration of Renewable Energy. Springer.

Abad, G., Lopez. J., \& Rodriguez, M. A. (2011). Doubly Fed Induction Machine. IEEE Press. 
Robert, F. S. (1993). Optimal Control and Estimation. Dover publications.

Vijay, V., \& Raja, A. (2012). Grid Integration and Dynamic Impact of Wind Energy. Springer.

Kesraoui, M., \& Chaib, A. (2016). Grid voltage local regulation by a doubly fed induction generator-based wind turbine. Wind Engineering, 41(1), 13-25.

Rui, S., \& Rui, X. (2015). The design and analysis of wind turbine based on differential speed regulation. Wind Engineering, 230(2), 221-229.

Yu, L., \& Zhenlan, D. (2012). Improvement of the low-voltage ride-through capability of doubly fed Induction Generator Wind Turbines. Wind Engineering, 36(5), 535-551.

\section{Appendix}

Table 1. WT parameters (Abad et al., 2011)

\begin{tabular}{ll}
\hline Nominal active power $\mathrm{P}_{\mathrm{N}}$ & $1.5 \mathrm{MW}$ \\
Nominal electrical torque $\mathrm{T}_{\text {elN }}$ or $\mathrm{T}_{\mathrm{g}}$ & $9555 \mathrm{Nm}$ \\
Stator voltage $\mathrm{V}_{\mathrm{SN}}$ & $690 \mathrm{~V}$ \\
Nominal generator speed $\eta_{\mathrm{go}}$ & $1800 \mathrm{rpm}$ \\
Speed range of generator & $900-1850 \mathrm{rpm}$ \\
Pole pairs & 4 \\
Blades diameter $d$ & $60 \mathrm{~m}$ \\
Nominal wind speed $\mathrm{V}_{\mathrm{wN}}$ & $12 \mathrm{~m} / \mathrm{sec}$ \\
Maximum power coefficient $\mathrm{C}_{\mathrm{p}}$ & 0.44 \\
Air density & $1.125 \mathrm{~kg} / \mathrm{m}^{3}$ \\
Nominal turbine speed $\eta_{\mathrm{to}}$ & $22.5 \mathrm{rpm}$ \\
Speed range of turbine speed & $9-23 \mathrm{rpm}$ \\
TSR optimum & 5.43 \\
Grid side components $(\mathrm{m} \Omega)$ & $\mathrm{R}_{\mathrm{g}}=0.33 \mathrm{X}_{\mathrm{g}}=31.4$ \\
\hline
\end{tabular}

Table 2. Medium voltage lines

\begin{tabular}{ll}
\hline Rated voltage $\mathrm{V}_{\mathrm{N}}$ & $25 \mathrm{kV}$ \\
Inductive reactance $\mathrm{X}_{\mathrm{o}}$ & $0.4 \Omega / \mathrm{km}$ \\
Resistance $\mathrm{R}_{\mathrm{o}}$ & $0.1 \Omega / \mathrm{km}$ \\
Length between buses 1-2 & $5 \mathrm{~km}$ \\
Length between buses 1-4 and 3-4 & $10 \mathrm{~km}$ \\
\hline
\end{tabular}

Table 3. Synchronous generator parameters (Pai et al., 2016)

\begin{tabular}{|c|c|c|c|}
\hline Rated voltage $\mathrm{V}_{\mathrm{N}}$ & $11 \mathrm{kV}$ & $\mathrm{D}$ axis open circuit time constant $\mathrm{T}_{\mathrm{do}}{ }^{\prime}$ & $4.5 \mathrm{sec}$ \\
\hline Rated power $S_{N}$ & 50 MVA & $\mathrm{Q}$ axis open circuit time constant $\mathrm{T}_{\mathrm{qo}}$, & $0.67 \mathrm{sec}$ \\
\hline Transient reactance on $\mathrm{d}$ axis $\mathrm{X}_{\mathrm{d}}$ & 0.25 p.u. & Inertia constant $\mathrm{H}$ & $0.87 \mathrm{sec}$ \\
\hline Reactance on $d$ axis $X_{d}$ & 1.65 p.u. & Stator resistance $\mathrm{R}_{\mathrm{s}}$ & 0.0045 p.u. \\
\hline Transient reactance on $\mathrm{q}$ axis $\mathrm{X}_{\mathrm{q}}{ }^{\prime}$ & 0.46 p.u. & Power angle operating point & $\delta_{0}=30^{\circ}$ \\
\hline Reactance on $\mathrm{q}$ axis $\mathrm{X}_{\mathrm{q}}$ & 1.59 p.u. & Bus 1 voltage operating point & $V_{1 q \mathrm{o}}=-0.052$ p.u. \\
\hline Subt. int.voltage on q axis Eq' operating point & $\mathrm{E}_{\mathrm{qo}}^{\prime}=0.68$ p.u. & Line current on $\mathrm{D}$ axis operating point & $\mathrm{I}_{\mathrm{Do}}=0.28$ p.u. \\
\hline Subt. int.voltage on d axis Ed' operating point & $E^{\prime} \mathrm{do}=0.22$ p.u. & Line current on $\mathrm{Q}$ axis operating point & $\mathrm{I}_{\mathrm{Qo}_{0}}=-0.1$ p.u. \\
\hline
\end{tabular}

\section{Copyrights}

Copyright for this article is retained by the author(s), with first publication rights granted to the journal.

This is an open-access article distributed under the terms and conditions of the Creative Commons Attribution license (http://creativecommons.org/licenses/by/4.0/). 